\title{
Patrimonios inmateriales, desarrollo rural y despoblación. La identidad como recurso
}

\author{
Aniceto Delgado Méndez | Centro de Documentación, Instituto Andaluz del \\ Patrimonio Histórico \\ Elodia Hernández León | Dpto. de Antropología Social, Psicología Básica y Salud \\ Pública, Universidad Pablo de Olavide \\ URL de la contribución <www.iaph.es/revistaph/index.php/revistaph/article/view/4525>
}

\section{RESUMEN}

Sin ser una cuestión novedosa, la despoblación de amplias zonas rurales se ha tornado una cuestión social relevante. El estancamiento socioeconómico de las poblaciones que habían centrado sus modos de vida en las actividades agrarias, y por ende su continuo vaciamiento, se intenta superar desde el ansiado desarrollo rural. En el orden global, entre las estrategias que se abordan para promoverlo, se encuentra un recurrente recurso basado en la patrimonialización de los aspectos culturales identificados como rurales.

Tras décadas de producción de conocimiento e intervenciones sobre el patrimonio cultural de estas zonas, nos enfrentamos al análisis de los procesos de patrimonialización cultural seguidos en el marco europeo de las políticas de desarrollo rural que arrancan a finales del pasado siglo desde un enfoque crítico con el paradigma clásico de qué es patrimonio cultural y por tanto concediendo a las activaciones de los patrimonios inmateriales un lugar preferente. Mas allá de una evaluación mecánica de los efectos del recurso al patrimonio para el desarrollo rural, exploramos las múltiples significaciones de estos procesos sociopolíticos y económicos desde el caso de una comarca andaluza.

\section{Palabras clave}

Desarrollo rural | Despoblación | Identidad cultural | Patrimonialización | Patrimonio cultural | 


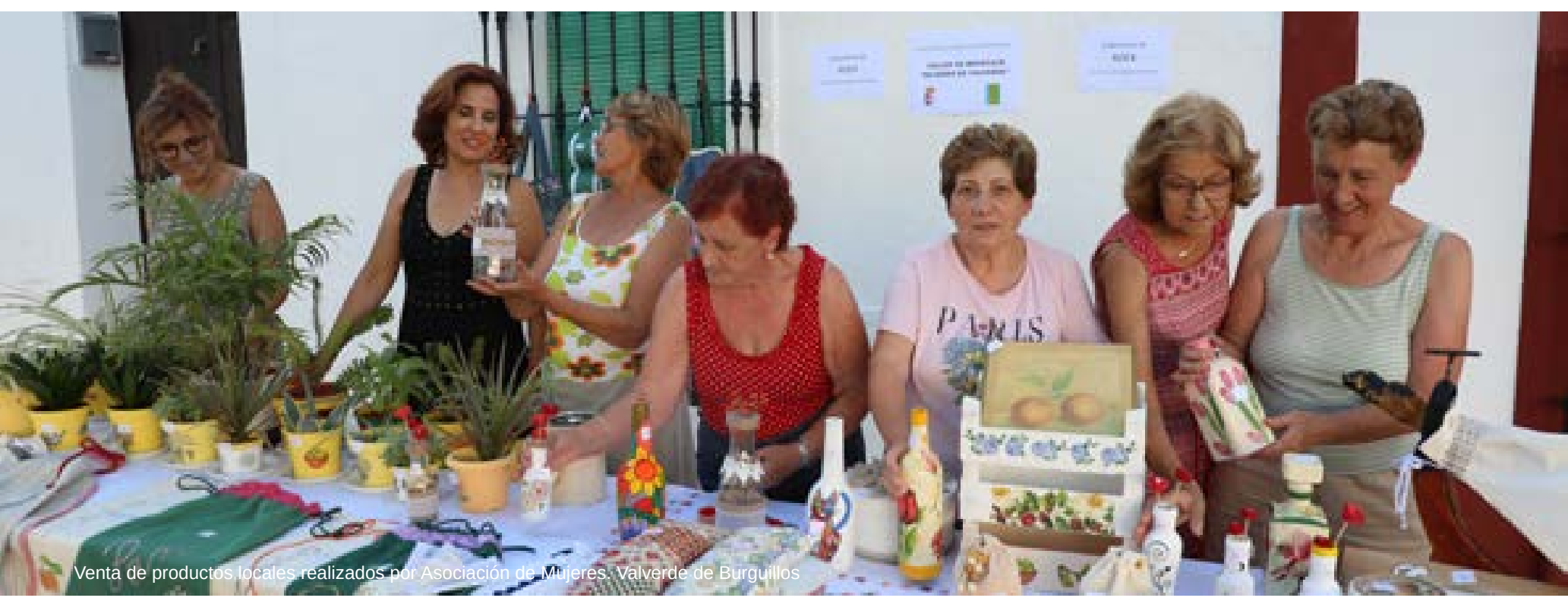

Intangible heritage, rural development and depopulation. Identity as a resource

\section{ABSTRACT}

Without being a new issue, the depopulation of large rural areas has become a relevant social issue. From the longed-for rural development there is a clear attempt to overcome the socioeconomic stagnation of the populations that had focused their lifestyles on agricultural activities, and therefore their continuous emptiness. In the global order, among the strategies that are approached to promote it, there is a recurrent resource based on the patrimonialization of the cultural aspects identified as rural.

After decades of production of knowledge and interventions on the cultural heritage of these areas, we face the analysis of the processes of cultural heritage followed in the European framework of rural development policies that started at the end of the last century from a critical approach with the classic paradigm of what is cultural heritage and, subsequently, giving the activations of intangible heritage a preferential place. Beyond a mechanical evaluation of the effects of the resource to heritage for rural development, we explore the multiple meanings of these socio-political and economic processes from the case of a region in Andalucia.

\section{Key words}

Rural Development | Depopulation | Cultural identity | Patrimonialiation | Cultural Heritage |

Cómo citar: DELGADO MÉNDEZ, A.; HERNÁNDEZ LEÓN, E. (2019) Patrimonios inmateriales, desarrollo rural y despoblación. La identidad como recurso. Revista PH [en línea], n. ${ }^{\circ}$ 98, 2019, pp. 150-171 <www.iaph.es/revistaph/index.php/revistaph/article/view/4525>

Enviado: 09/09/2019 | Aceptado: 18/09/2019 | Publicado: 04/10/2019 


\section{INTRODUCCIÓN ${ }^{1}$}

1

El presente texto se enmarca en el proyecto "patrimonio inmaterial y políticas culturales: desafíos sociales, políticos y museológicos" (PGC2018-096190-B-I00). IP: Xavier Roigé de la convocatoria 2018 de Proyectos de I+D de Generación de Conocimiento Ministerio de Ciencia, Innovación y Universidades.

\section{2}

El cambio de terminología: de desarrollo agrario a desarrollo rural (RODRÍGUEZ GONZÁLEZ, 2004: 11) no es un paso caprichoso sino que responde a una transformación en la forma de concebir la intervención en los territorios en los que la actividad agraria es la predominante.
Peñalba de San Esteban (Soria) | | foto Aniceto Delgado Méndez, autor de todas las imágenes que ilustran este artículo si no se indica lo contrario
La "España Vacía", el reto demográfico y en definitiva la despoblación de extensas zonas del territorio español, es un tema de actualidad. Una cuestión social relevante de la que se ocupan la literatura académica, las instituciones públicas y muy diferentes entidades y agentes sociales que están presentes en el desarrollo de estrategias orientadas a entender los significados de este fenómeno y a procurar soluciones que lo detengan.

Sin embargo, esta actualidad no es reflejo de una emergencia reciente. La identificación del problema de la despoblación, que se evidencia como efecto del éxodo rural de mediados del pasado siglo $X X$, se vincula con la necesidad de modernización y del desarrollo socioeconómico de las poblaciones que habían centrados sus modos de vida en las actividades agrarias. Despoblación y desarrollo rural, antes agrario, quedarán vinculados. Tras una primera etapa en la que el modelo costoso de protección de precios y en la apuesta por el liberalismo del sistema global, la intensificación de la agricultura como estrategia de desarrollo, se demuestra inviable para amplias áreas, principalmente las de montaña, cuyas condiciones no permiten una adaptación a la externalización de un sistema productivista. Es entonces cuando se producirá la translación terminológica, de desarrollo agrario a desarrollo rural2 $^{2}$ y el modelo productivista pierde vigencia frente al precepto de la diversificación económica, esto es, el desarrollo de otras actividades no agrarias.

Desde los años ochenta del pasado siglo veinte, las poblaciones rurales estarán atrapadas por un sistema agroalimentario en la era global que se traduce

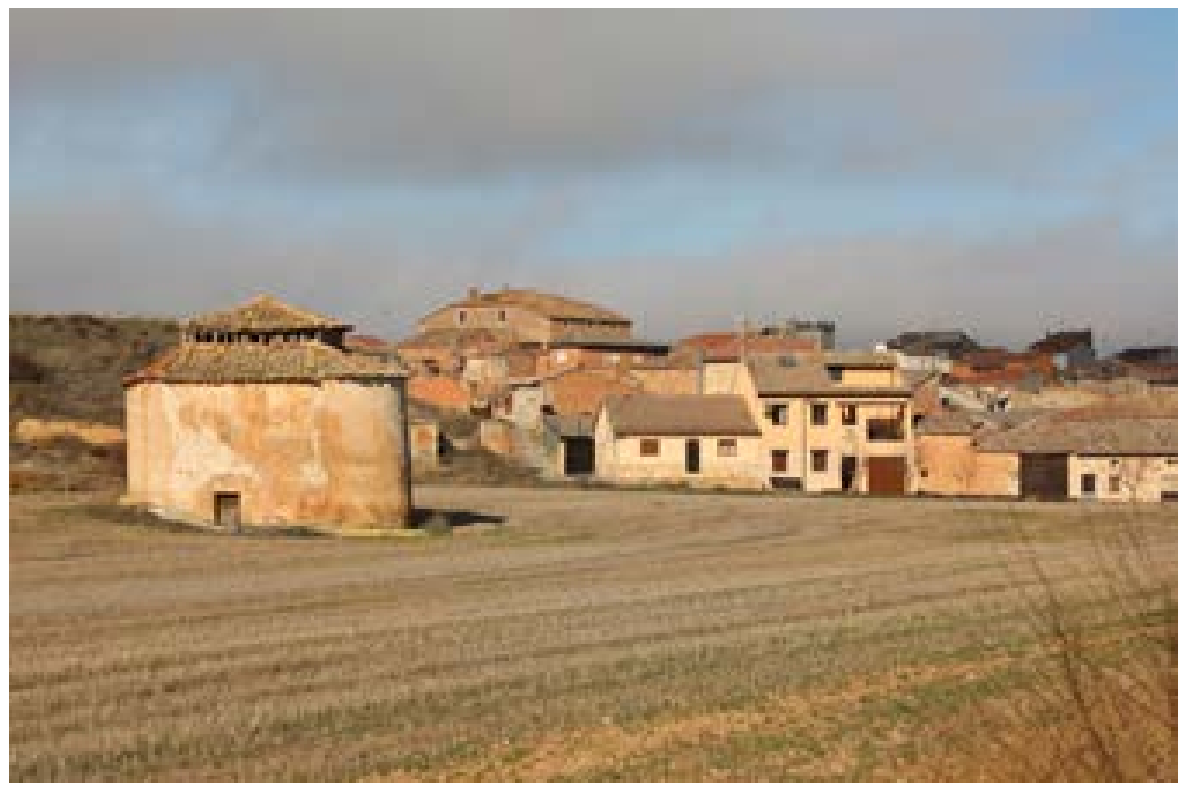


en un distanciamiento del control de las producciones de los sujetos y los contextos locales: "El capital global tiene ahora la posibilidad de 'optimizar' el aprovechamiento de las condiciones específicas de lo local (...) los territorios son ahora utilizados con mayor intensidad que nunca de modo que la llamada 'desterritorialización' debe ser entendida como falta de compromiso o enraizamiento del capital con los lugares concretos" (DELGADO CABEZA, 2010: 22)

De hecho hace ya casi treinta años que se pusieron en marcha las políticas comunitarias enfocadas a la supervivencia de un mundo rural que continuaba enfrentándose al fantasma de la despoblación.

Se imaginaron entonces intervenciones que atajaran los indicadores de estancamiento y fijaran las poblaciones que hasta el momento habían tenido como sector productivo prioritario el agropecuario. Así se estableció el objetivo de promover el desarrollo rural para la revitalización de un mundo que "desaparecía" a pasos agigantados.

En adelante las políticas de los estados europeos irán encaminadas tanto a paliar los efectos perversos que la globalización agroalimentaria desencadenan en el medio rural, como a garantizar que la inserción en los nuevos sistemas se realiza adecuadamente. Las estrategias orientadas a la adaptación del mundo rural a las necesidades y "generosidades" procedentes de la globalización han contado con el beneplácito, en primer lugar, de los estados y posteriormente de las instituciones regionales y comarcales que vieron en estas políticas comunitarias la salvación a situaciones complejas desde las lógicas sociales, políticas y económicas.

Entre las directrices emanadas de las instituciones que velaban por este nuevo paradigma, destacaban los discursos que giraban en torno al patrimonio cultural y su "puesta en valor". A lo largo de estos años, y estrechamente relacionados con la evolución del concepto de patrimonio cultural y la definición de los bienes que lo integran, se han producido importantes transformaciones respecto al campo de lo patrimonial en relación con qué elementos se definen como patrimoniales, cuáles son los discursos autorizados que legitiman la acción patrimonial y sobre todo quiénes son los agentes en los que se deben sustentar los procesos de patrimonialización (SMITH, 2006; 2011) de tal forma que ya no debemos preguntarnos qué es patrimonio sino cuándo hay patrimonio (GARCÍA CANCLINI, 2010: 69), incidiendo en el proceso de selección social del patrimonio antes que en la definición apriorística de los bienes patrimoniales. Así, en nuestro contexto tras el periodo de la eclosión identitaria promovida por las autonomías a finales de los años setenta y principios de los ochenta del pasado siglo veinte, asistimos en las últimas décadas a una nueva búsqueda de referentes identitarios que, bajo el paraguas del patrimonio, sirvan para definir propuestas de "desarrollo", principalmente de los ámbitos rurales. 
Chozo y pajar abandonado. Valencia del Ventoso (Badajoz)

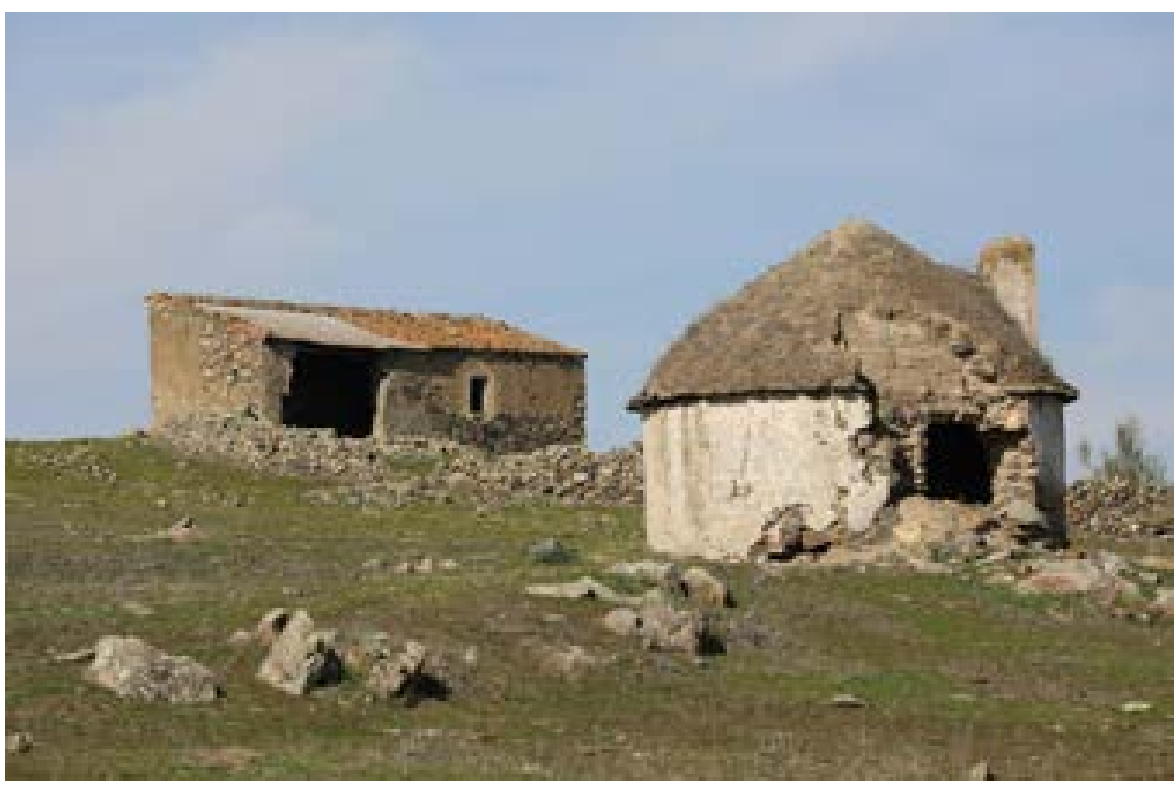

De esta forma lo local jugará un papel central en el panorama de la producción patrimonial, papel que les estaba vedado por las topografías jerarquizadas de un patrimonio engrosado y liderado por las grandes obras monumentales de los contextos urbanos. Asistiremos por tanto a la inauguración de un periodo en la era global en el que las políticas patrimoniales, la gestión centralizada del patrimonio, se verá rebasada por las acciones y nuevos reconocimiento de valores culturales, antes ausentes, en el mundo rural.

Pero no se trata solo de analizar en exclusiva la significación que tiene para el campo de actuación del patrimonio estas emergencias de patrimonios antes olvidados, sino desde una perspectiva antropológica, incidir en la necesidad de afrontar el fenómeno de la creciente importancia del patrimonio desde sus múltiples funcionalidades y significaciones. Mas allá de las bondades de promoción del turismo que se le suponen a las intervenciones sobre el patrimonio, son muchos los aspectos que hay que considerar para enfrentar el análisis que las implicaciones que el juego patrimonial tiene en el ansiado desarrollo rural y por ende en los procesos de despoblamiento del medio rural.

Si solo de eso se tratara, presentaríamos un panorama negativo dado que las intervenciones sobre el patrimonio rural y otras medidas e inversiones no han conseguido promover suficientemente la empleabilidad y el dinamismo de las economías locales respondiendo a las expectativas con las que se forjó el salvavidas del "turismo rural" que, irrumpiría, ante unas sociedades locales escépticas y apesadumbradas por las transformaciones en 
sus modos de vida desencadenadas por las nuevas condiciones que los sistemas agroalimentarios imponían. Como se ha reconocido no sólo para el ámbito andaluz: "El papel del turismo rural como actividad potenciadora del desarrollo rural ha sido una de las cuestiones más debatidas en las últimas décadas. Es indudable que las inversiones y el empleo directo e indirecto generado por el turismo rural han sido beneficiosos para las áreas rurales. Sin embargo, inicialmente se magnificó el papel que podía jugar el turismo rural en pro del desarrollo de las áreas rurales, razón por la que esta actividad, por sí sola, no puede solventar los problemas sociodemográficos (pérdida de población, desempleo, envejecimiento) y económicos que padecen las áreas rurales de Extremadura. La dinámica demográfica de los últimos 25 años en Extremadura muestra una pérdida continuada de habitantes en los municipios con menor peso demográfico y un envejecimiento que se ha hecho más acusado (RENGIFO GALLEGO; SÁNCHEZ MARTÍN, 2016: 287).

Indudablemente la vinculación entre desarrollo rural y patrimonio debe de ser abordada desde la complejidad. Si solo atendemos a los resultados económicos de la ecuación turismo rural-recursos patrimoniales, no sólo tendremos que proclamar el fracaso de una vinculación que no es mecánica ni directa sino que estaríamos compartiendo una visión del patrimonio cultural que lo reduce a su valor económico, promoviendo sólo la construcción de unos dispositivos patrimoniales a medida del consumidor, ese consumidor urbano que demanda naturaleza y tradición. Con ello se estarán horadando las bases de un enfoque adecuado de qué entendemos por desarrollo sostenible y por patrimonio. Se ponen en peligro además el alcance a largo plazo de los procesos sociales generados en la patrimonialización resultando la desapropiación de las poblaciones locales de su propio patrimonio y de su futuro, es decir, actuando en contra de las posibilidades de sostenimiento de las poblaciones rurales.

Por tanto, compartimos con Camarero: "La necesidad de contemplar la dimensión social de la sostenibilidad, además de la medioambiental y la económica, pues mas allá de lo cambios en los sistemas productivos, el desarrollo también está relacionado con la construcción y el fortalecimiento de las redes de sociabilidad, que posibilitan las formas de vida, de la población, con más o menos calidad, tanto rural como urbana" (CAMARERO; CRUZ; GONZÁLEZ et ál., 2009: 24). Y nos acercaremos a un análisis de los procesos de patrimonialización y de los programas de desarrollo multidimensional con un enfoque en los sujetos y no en los objetos. Sólo de esta forma nos parece posible evaluar los efectos de las políticas de desarrollo rural que en su vertiente patrimonial tienen en el medio rural andaluz.

Nos centraremos para ello en los procesos de patrimonialización de elementos caracterizados por su inmaterialidad, las fiestas y recreaciones históricas 
Nos referimos a la comarca Sierra de Arace na y Picos de Aroche tal como es delimitada en los programas de desarrollo rural Leader y Proder en sus sucesivas ediciones. Está compuesta por 29 municipios, los mismos que se incluyen total o parcialmente en el parque natural del mismo nombre, más el municipio de Rosal de La Frontera. Existe entre ellos una gran variabilidad en cuanto a las dimensiones y concentración de población. Solo un municipio, Aracena, cuenta con más de cinco mil habitantes y un crecimiento demográfico que es negativo en la gran mayoría de las poblacio nes (cinco tienen más de dos mil, trece entre dos mil y quinientos, y once por debajo de los quinientos). Desde lo años setenta, década en la que se aprecia una bajada abrupta de la población, la comarca pierde efectivos aunque sostenido y con el crecimiento positivo en al menos seis núcleos (http://www.gdrsaypa es/estrategia-de-desarollo-local-participativo/ diagnostico-territorial/).

La Sierra tiene como actividad principal la agropecuaria, el aprovechamiento ganadero y forestal de las dehesa que compone un paisaje propicio para las actividades de naturaleza. Destacan también los olivares y el castañar y las huertas aunque presentan problemas de productividad y abandono de explotaciones. La industria más importante, además de se centra en la manipulación y transformación de productos agrarios (aceites y conservas) y, sobre todo, en la elaboración de productos cárnicos, especialmente jamones (Jabugo, El Repilado, Aracena...)

Las actividades cinegéticas que ya estaban presente en el área han cobrado mayor relevancia gracias al turismo. Un turismo, procedente de las capitales andaluzas de Sevilla y Huelva, que establece la segunda residencia seducidos por una mejora sustancial en las vías de comunicación y un aumento de los servicios básicos. Esta afluencia e incremento de las segundas residencias, tanto por la rehabilitación como por la nueva construcción, constituyó un nuevo panorama de cierto pulso en muchos de los pequeños pueblos que se habían quedado semidespoblados. Es cierto que esta afluencia se aprecia sobre todo en que son paradigmáticas de esta multiplicidad de sentidos con los que hay que abordar el patrimonio como recurso para el desarrollo rural ejemplificando en las activaciones patrimoniales de una comarca andaluza ${ }^{3}$. Ello implica arrancar, como lo hacíamos, de las iniciativas desencadenadas en el marco de la Unión Europea que promoverán actuaciones directamente relacionadas con el sentido que adquirirán los procesos de patrimonialización y así poder desentrañar la vinculación entre el desarrollo y el patrimonio en el medio rural.

\section{LOS PROGRAMAS DE INTERVENCIÓN CONTRA LA CRISIS Y SUS EFECTOS DESPOBLADORES}

Como señalábamos, son varias las décadas de puesta en marcha de actuaciones en el marco de los programas europeos que abordarán las situaciones de precariedad del medio rural. Desde el desarrollo del primer programa conocido como Leader I (1991-1993), se suceden iniciativas comunitarias encaminadas al desarrollo rural. El primer programa LEADER (Liaison Entre Actions de Développement de l'Économie Rurale) fue puesto en marcha como una iniciativa piloto dirigida al ámbito rural y con el objetivo claro de intentar frenar el despoblamiento de las zonas rurales a través de la diversificación de la economía. Siguiendo esta línea comunitaria, el Estado español creó un programa similar a los Leader y que recibió el nombre de PRODER (Programa de desarrollo y diversificación económica de las zonas rurales).

Los programas LEADER y PRODER, en sus sucesivas ediciones, han tenido gran trascendencia en el medio rural andaluz ${ }^{4}$, no sólo por ser fuentes de financiación sino más bien por los procesos de reconocimiento del patrimonio como principio estratégico de dinamización socioeconómica de unas poblaciones que se resentían de la dramática pérdida de efectivos y se encontraban marginadas con respecto a los núcleos urbanos principales. La diversificación económica se concentró en el sector turístico, abundando entre las iniciativas emprendidas las dirigidas al desarrollo de equipamientos como casas rurales, restaurantes, centros de interpretación, museos y también la rehabilitación de molinos, haciendas, fábricas, casas que se reutilizan como equipamientos para los visitantes, además de la restauración y mejora de la accesibilidad de yacimientos o monumentos (TASSARA ANDRADE, 2002: 85-91). Las inversiones se dirigieron principalmente al desarrollo infraestructural en el proceso de construcción de una oferta turística. En este proceso se promueve la identificación entre el escenario turístico y el patrimonio, desencadenándose la reconstrucción o reinvención de los patrimonios locales materiales o inmateriales.

No obstante aún reconociendo que en el origen el fomento del sector turístico fue el objetivo prioritario también es cierto que la valorización del patrimonio rural va emergiendo en la definición de los propios programas. Si en 
el LEADER II y en el PRODER ya se encuentran como medidas específicas para el desarrollo de la actividad turística, en las sucesivas etapas de Leader Plus y del PRODER 2000/2006 "se afianza en los objetivos y en las de actuación... Especialmente en el Leader Plus, donde la Valorización del patrimonio natural y cultural adquiere el rango de objetivo general" (BARRERA LINARES, 2010: 172). Para finalmente incluirse en el Lidera (2007-2013) como un línea de intervención que da entrada a las inversiones sobre el patrimonio y ello se interpreta como "una ruptura del idilio entre el patrimonio cultural y el turismo rural que se integra en otro programa, el de Dinamización Económica de las Zonas rurales. Por primera vez se asocia la conservación y protección del patrimonio rural a la calidad de vida de las zonas rurales, por los destinatarios finales de las inversiones culturales del programa Lidera pasan a ser los residentes y no los visitantes..." (BARRERA LINARES, 2010: 172). Más recientemente, en las estrategias de desarrollo local participativo y las convocatorias Leader 1014-2029, el conocimiento, la conservación y protección del patrimonio rural continúa siendo una línea de ayudas (http:// www.gdrsaypa.es/wp-content/uploads/documentos/lineasayuda17.pdf).

La amplia historia de puesta en marcha de los programas europeos no están exenta de fracasos e incoherencias. De hecho, desde un primer momento, se pusieron sobre la mesa algunas críticas sobre la adecuación de un marco de actuación que había nacido con el referente de las zonas rurales del norte europeo (PÉREZ FRA, 2004: 7). En estas últimas, la agricultura se había adaptado a los nuevos contextos y ritmos. Se trataba de sociedades más dinámicas en las que la pluralidad de actividades añade valor y no de áreas estancadas y deprimidas. Tanto es así que se demostró una relación directa entre el dinamismo del área rural andaluza y el éxito de los programas (TASSARA ANDRADE, 2002: 90)

Sin embargo, como establecíamos al principio, abriendo el foco sobre el campo del patrimonio cultural y sobre la forma en el que lo entendemos, la evaluación de la incidencia de estos programas resulta diferente si atendemos al análisis de las construcciones y reafirmaciones de territorios culturales que conllevan los procesos de activación de los recursos culturales puestos en marcha a partir del llamado desarrollo rural. Y ello es posible por las características de la metodología promocionada por estos programas: el enfoque desde el territorio (PÉREZ FRA, 2004: 10).

Los requisitos de participación y cooperación de los agentes locales fueron premisas necesarias desde el inicio. Se crearon los denominados Grupos de Acción local que se encargaban de diseñar y liderar los programas en el territorio. La obligatoriedad de la articulación de las distintas instituciones y grupos sociales para optar al proyecto y la necesidad de recurrir a la cooperación de las diferentes localidades con un referente territorial supramunicipal tuvieron y continúan teniendo una incidencia que no hay que despreciar. los fines de semana y períodos de vacaciones, pero ha tenido una incidencia notable en el aumento de negocios hosteleros. Este aumento de visitantes, así como el desarrollo del turismo rural, han reforzado también el sector de la construcción que llegó a ser fuente de empleo sobretodo con anterioridad al inicio de la crisis financiera.

Los fondos europeos de la iniciativa LEADER y el Programa de desarrollo PRODER, aprobado en España para la intervención en las regiones objetivo 1, afectan al $50 \%$ de la población andaluza y a un 92\% del territorio andaluz.

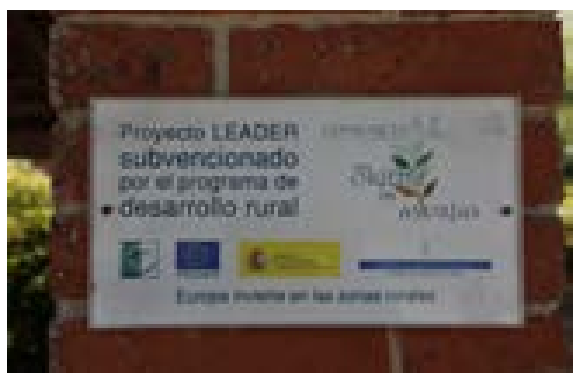

Cartel anunciando Proyecto de Desarrollo Rural. Llanes (Asturias) 

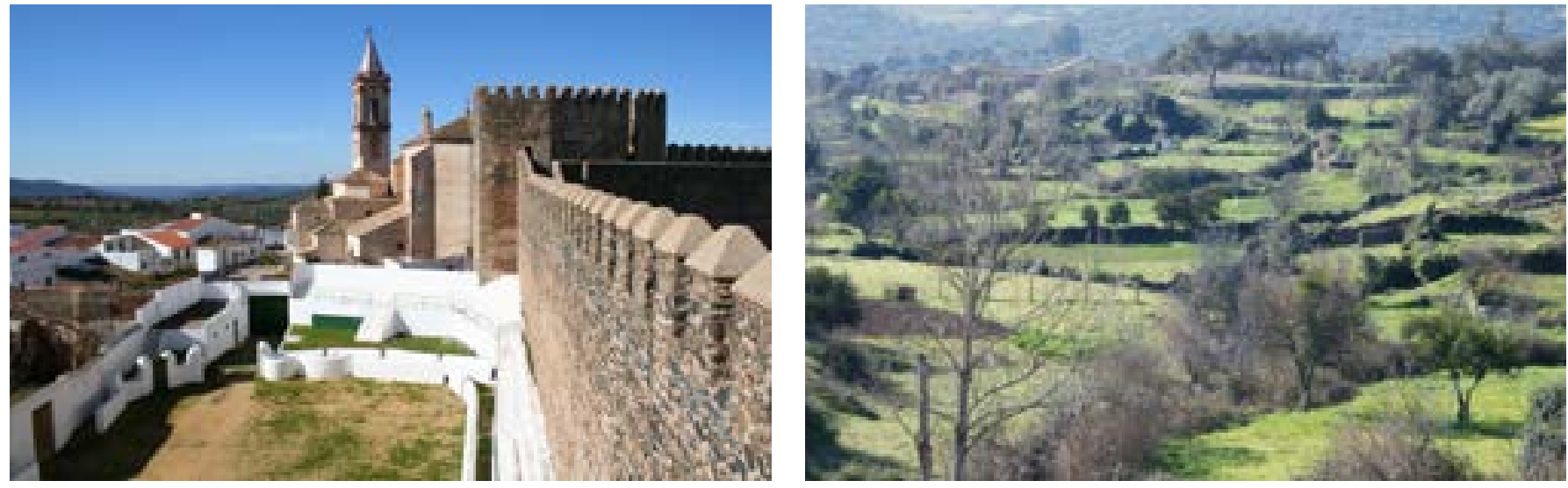

Detalle Castillo, Iglesia parroquial y plaza de toros. Cumbres Mayores (Huelva)

Paisaje serrano. Arroyomolinos de León (Huelva)

En Andalucía la dimensión de identificación con el territorio que promueven estos programas tiene una especial importancia porque la caracterización de áreas potenciales de actuación para la iniciativa europea tiene un claro referente: las comarcas. De hecho los grupos de desarrollo rural promueven, para la planificación y la ejecución de los programas, la identificación del ámbito de actuación con comarcas, usando esta denominación como referente del territorio objeto de las iniciativas europeas y ello es innovador puesto que en Andalucía no existía un proyecto unívoco de mapa comarcal5. Al no existir éste había una convivencia de diferentes delimitaciones funcionales según los fines políticos sectoriales (judiciales, sanitarios, educativos...) junto a la creación de mancomunidades, agrupaciones de municipios, promovidos desde las diputaciones para el desarrollo de servicios infraestructurales entre municipios vecinos. tonómica para el establecimiento de un mapa comarcal andaluz en los años ochenta, a tra vés del Proyecto de Comarcalización de 1983 (Junta de Andalucía, 1983), no obtuvo un resultado satisfactorio, no llegó a implantarse a surgir numerosas críticas con respecto a las áreas de adscripción de las diferentes localidades. En la base de este fracaso encontramos concepciones divergentes de estos espacios desde su entendimiento como meras áreas funcionales a su reconocimiento como territorios histórico-culturales (HERNÁNDEZ LEÓN, 2008).

Se crearon entonces las denominadas comarcas LEADER o PRODER, lideradas por los agentes locales que constituyeron los "grupos de acción local". A partir de entonces se produjo la activación del referente comarcal y en definitiva de la comarca como territorio cultural. La promoción de este nuevo marco de adscripción se hace a partir de la activación del patrimonio natural y cultural local, y, por supuesto, con las estrategias de desarrollo económico local entroncadas con las iniciativas europeas.

Para la creación de las comarcas, los grupos de acción local toman como referencias territoriales previas, articulaciones vecinales y aspectos históricos culturales que consideran compartidos. Van a ser esas agrupaciones la que, con el objetivo de potenciar el turismo rural y el desarrollo sostenible, reconstruyan o construyan unos referentes necesarios, reconocibles y deseables sobre esa amalgama político-administrativa y sectorial.

Por tanto, más allá de ser valorados por su impacto económico o como amortiguador de la reconversión agrícola, los procesos de patrimonializa- 
ción surgidos como efectos directos o colaterales a las actuaciones planificadas en los programas europeos tienen una incidencia como promovedores de la vinculación social de los distintos municipios (RENTING, 2010: 107), de creación de un capital simbólico que a la postre son valores de naturaleza y tradición que identifican a los productos de estas tierras y de revalorización de unos recursos culturales, inmateriales en su mayoría, capaces de avivar los sentimientos de pertenencia de sus poblaciones (HERNÁNDEZ LEÓN, 2008: 94). Todo ello necesario para la dinamización económica del territorio y para la mejora de la cotidianeidad de sus vecinos aunque sea en la línea de hacerla más urbana.

\section{LOS PROCESOS DEL PATRIMONIALIZACIÓN DE LAS CULTURAS TRADICIONALES. EL CASO DE LA SIERRA DE ARACENA Y PICOS DE AROCHE}

El interés por lo tradicional ha venido de la mano, en numerosas ocasiones, de la resignificación del mundo rural y de sus prácticamente desaparecidas formas de vida. Recuperar las recetas tradicionales, antiguas fiestas, elementos de la arquitectura tradicional, las músicas tradicionales y otras manifestaciones, se articulan en gran medida bajo procesos que pretenden defender los valores del mundo rural en contraposición a los modelos procedentes del ámbito urbano.

Este proceso, la patrimonialización del territorio y la continuada búsqueda de valores que permitan definir o reconstruir las identidades locales, tiene en el patrimonio etnológico un referente de primer orden sobre el que moldear discursos y recursos. En este sentido, la evolución de las teorías patrimonialistas ha aportado un significativo valor añadido a todas estas expresiones procedentes de la tradición y el mundo rural, subrayando la importancia que históricamente se ha dado a las expresiones festivo-ceremoniales. Las fiestas, por ejemplo, ya no son sólo el reflejo de la estructura social y los procesos históricos de un determinado colectivo (grupal, local, comarcal, étnico), sino que también los representan como destacadas señas de identidad (MORENO NAVARRO; AGUDO TORRICO, 2012).

Esta consolidación del valor simbólico atribuido a los bienes de carácter etnológico (fiestas, alimentación, músicas...) ha producido una enorme transformación en los discursos vinculados con el desarrollo rural y sobre todo en las políticas que versan sobre la despoblación. La importancia de estos bienes como expresión de identidades colectivas marca un nuevo contexto en la valoración de aquellos elementos que conforman el patrimonio cultural, aunque como indica Prats: "Que el patrimonio se halle estrechamente vinculado a la construcción identitaria no es ninguna novedad. De hecho nació para contribuir a fundar y fundamentar identidades. La novedad, en todo caso,

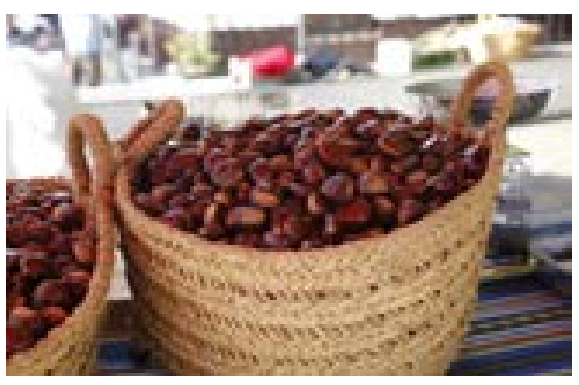

Venta de cesto de castañas. Fuenteheridos (Huelva)

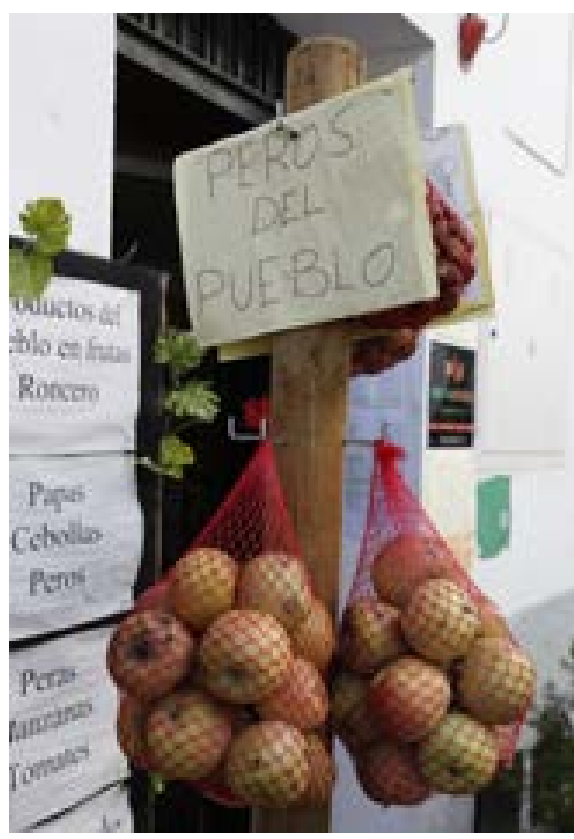

Productos locales en venta. Fuenteheridos (Huelva) 
6

Ocho años después estas jornadas comenzaron a celebrarse anualmente en cada uno de los municipios. En 1995 se creó la Federación de Asociaciones de la Sierra de Huelva. Inicialmente la constituyeron diez, siendo veinte en la actualidad. es que este vínculo se haya extendido a todos los niveles. (...) El patrimonio (y también la antropología) están contribuyendo a dibujar un mapa mucho más complejo y multidimensional de la realidad presente tal y como es vivida por sus mismo protagonistas, un mapa necesariamente evolutivo" (PRATS, 2014: 337).

En los procesos de "revitalización" e incluso "invención" de fiestas, festivales de música tradicional y otras manifestaciones, observamos la importancia que ha jugado y sigue jugando esta mirada patrimonialista (y patrimonializadora) sobre viejas tradiciones, actualizadas a los nuevos contextos. En este proceso de puesta en valor de la tradición, es importante señalar, al menos para el caso analizado, que la selección de referentes del pasado se articulan en torno a una resignificación de los mismos y su permanente actualización.

En la Sierra de Aracena y Picos de Aroche, los procesos de activación han conseguido no solamente la promoción de visitas sino principalmente la toma de conciencia sobre el valor patrimonial del territorio (HERNÁNDEZ LEÓN, 2009). Ya en la década de los ochenta, se organizaron por parte de los socios de las asociaciones culturales serranas que actuaban por el estudio y defensa del patrimonio histórico-cultural las primeras jornadas de patrimonio de la sierra (1986) ${ }^{6}$. Paralelamente a la promoción de los conocimientos sobre los bienes del patrimonio de la comarca, se denunciaron su estado de conservación, intentando, de esta manera, atraer a la lejana y mal comunicada Sierra diversos fondos para la restauración e intervención, principalmente sobre yacimientos, ermitas, castillos y, en general, sobre las obras más monumentales.

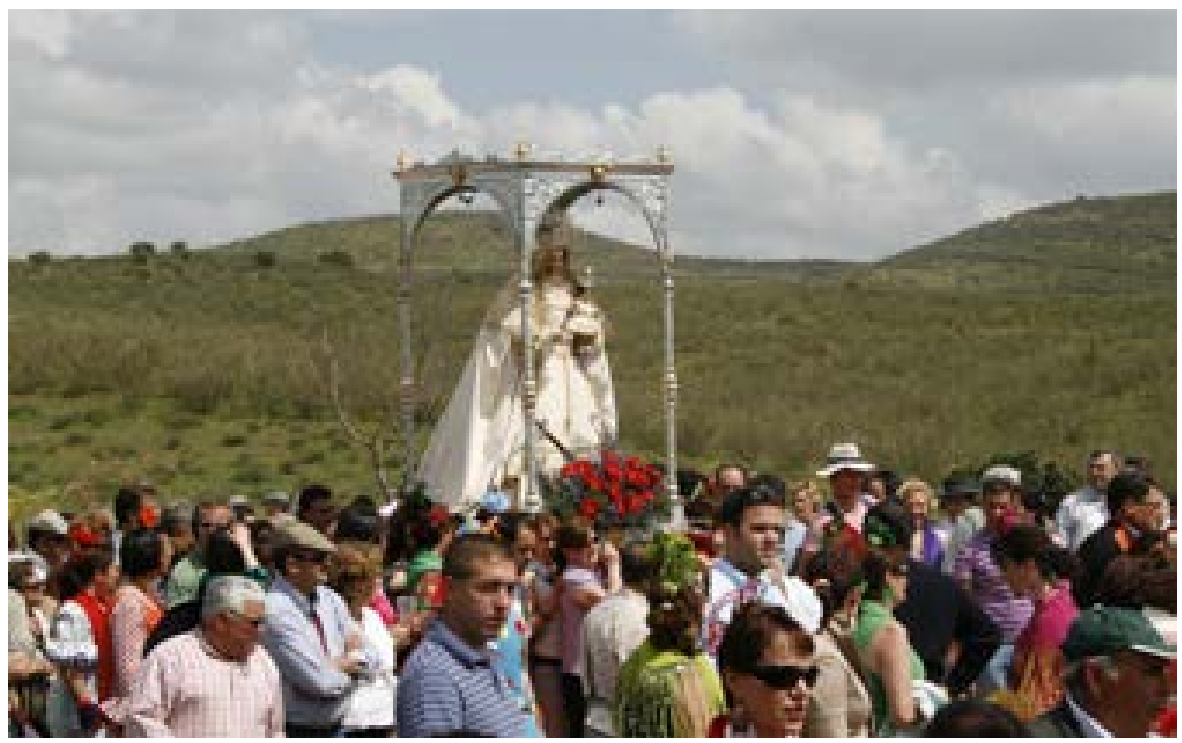


Si en un primer momento los procesos de patrimonialización se articularon en torno al patrimonio monumental, en la actualidad ocupan un papel principal las acciones desarrolladas sobre aquellos bienes de carácter etnológico que dan especificidad a esta comarca serrana. Los rituales festivos, la gastronomía, la creación de festivales identificados con el pasado histórico de determinadas poblaciones, la creación de espacios museísticos y otros aspectos, conforman un interesante texto para el análisis de las políticas culturales orientadas no al que visita sino fundamentalmente al que vive en estos espacios.

Aquí la comunidad muestra el patrimonio del que se siente "orgulloso", no sólo como una selección realizada por expertos ajenos a los contextos locales sino por el impulso generado desde las entidades y asociaciones del territorio. La experiencia serrana es por tanto un modelo no exportable a otras comarcas andaluzas en las que la realidad es bien distinta. En las últimas décadas, la colaboración entre instituciones públicas y privadas, así como el importante papel jugado por el grupo de desarrollo rural y los ayuntamientos, han marcado un proceso donde la activación del patrimonio cultural ha sido clave.

La diversidad de activaciones patrimoniales viene acompañada del reconocimiento de los valores de esta comarca serrana y del afianzamiento identitario por parte de sus vecinos. A ello debemos sumar el papel que han tenido en estos procesos los agentes locales de desarrollo rural, como hemos señalado más arriba, como impulsores de dinámicas orientadas al reconocimiento local y comarcal.

Sin duda que esa idea de comarca, ausente en otros territorios, es la que ha permitido que, aún sin perder de vista las especificidades locales, se desarrolle una propuesta consensuada sobre los valores naturales y culturales de la Sierra de Aracena y Picos de Aroche (HERNÁNDEZ LEÓN, 2008).

Entre los recursos procedentes de la cultura tradicional y el desarrollo de activaciones en clave patrimonial y turística, destacan aquellas que tienen en la gastronomía el eje de sus actuaciones. En este sentido nos encontramos con ejemplos dedicados a la recuperación de "platos típicos", la promoción de algún producto local, o la puesta en marcha de ferias de muestras donde poder encontrar una variedad de bienes relacionados con la alimentación local e incluso comarcal.

Algunas de estas activaciones han dado lugar a la consolidación de fiestas y el desarrollo de actividades paralelas en torno al elemento central seleccionado. Prueba de esto son por ejemplo la fiesta del melocotón de la Nava, la matanza vegetal de Calabazares, las ferias del Jamón de Aracena o Santa Olalla del Cala, o los concursos nacionales de cortadores de jamón de Jabugo. 
Embotellando tomates. Almonaster la Real (Huelva) | foto Fondo gráfico IAPH (Erica Bredy)

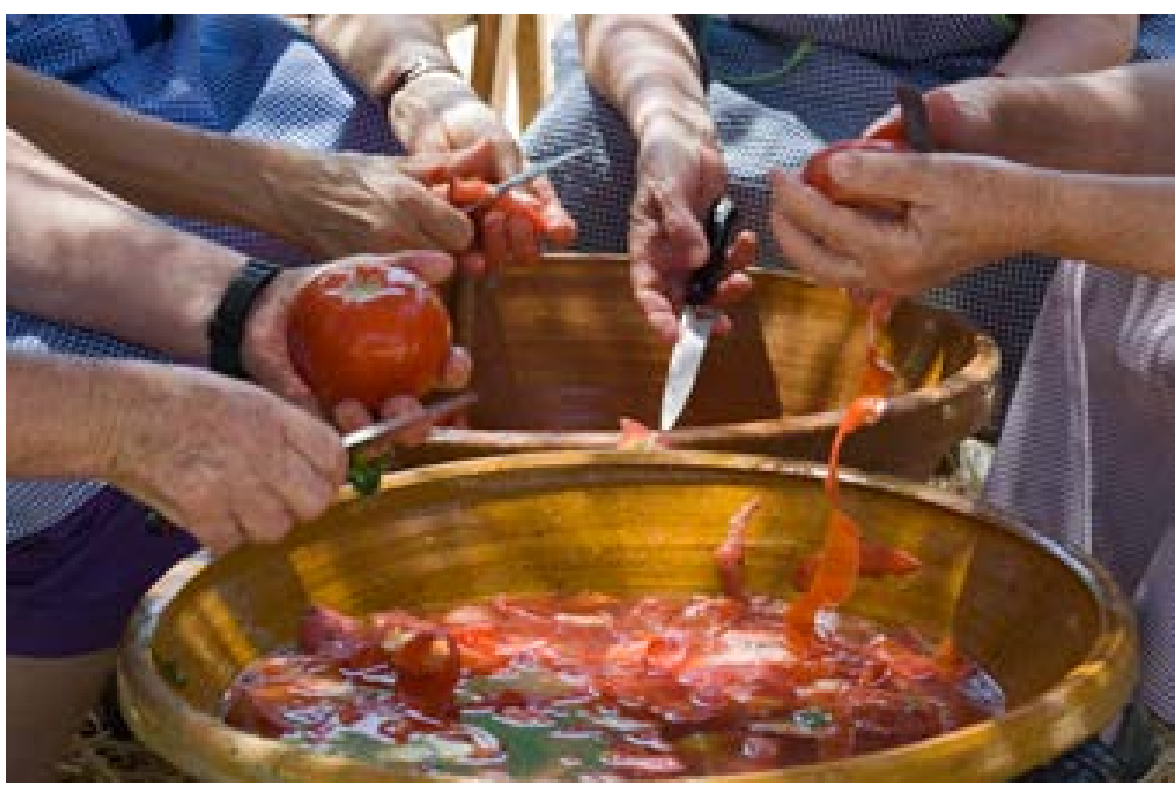

Otra de las propuestas encaminadas a la continuidad de tradiciones y los valores vinculados con estas son las recreaciones de la "matanza del cerdo", actividad presente en la Sierra de Huelva y en otras comarcas cercanas. Organizadas por instituciones tales como ayuntamientos, asociaciones culturales y otras, a diferencia de las matanzas domiciliarias, se trata de un acto colectivo donde se recrean algunos de los elementos que conforman la "matanza tradicional" y donde adquieren especial relevancia todo lo relacionado con la degustación de los productos derivados del cerdo. Asistimos a la creación de fiestas y jornadas gastronómicas que, principalmente en los meses de invierno, escenifican una actividad que ha jugado un papel fundamental en el ámbito doméstico d este territorio serrano.

El término "matanza" es usado también para el desarrollo de una fiesta que se viene celebrando desde el año 2003 en la aldea de Calabazares (Almonaster la Real, Huelva) y cuyo nombre es "la matanza vegetal". En esta ocasión el eje alrededor del cual se articula la celebración no es el cerdo sino los productos de la huerta serrana. Los objetivos principales de esta actividad que se lleva a cabo cada dos años son la promoción de los cultivos ecológicos de la huerta tradicional de esta comarca y dar a conocer la biodiversidad y el patrimonio etnográfico relacionado con esta actividad.

La relación entre la matanza del cerdo y el embotellado de tomate está en el origen de esta celebración serrana y la activación de una tradición, aun presente en la época estival. Como indica Cantero "Si la matanza marca la llegada del invierno, embotellar sella el verano y anuncia la llegada del otoño. La matanza y embotellar aúnan faena y congregación lúcida, la tarea y el 
juego, previsión y solidaridad. Embutir y embotellar conllevan gestos materialmente precisos y simbólicamente ambiguos que dan pie a una liberación de la palabra, de las actitudes y de los semblantes" (CANTERO, 2000).

Los usos de la historia como modelo de recreación y el desarrollo de propuestas orientadas a la producción de actividades que reclaman ese pasado ha dado lugar a la construcción de festivales donde, principalmente la Edad Media, ha sido elegida como el periodo ideal a recrear y valorar.

En estos casos las activaciones se articulan en torno a grandes hitos patrimoniales que se convierten en referentes monumentales de las localidades en la cuales se llevan a cabo. El pasado "glorioso" tiene presencia en arquitecturas que evidencian la relevancia de una población en un momento histórico determinado. Actividades pensadas para la atracción de visitantes que no obstante cuentan con la implicación de la población local dispuesta a vivir la nueva fiesta.

Entre los ejemplos que podemos encontrar en la sierra de Huelva se encuentran las Jornadas de Cultura Islámica de Almonaster la Real, un evento de gran importancia dentro del calendario anual de actividades de esta localidad serrana. Cuando llega el mes de octubre, en torno al doce, las calles del centro se convierten en un espacio de encuentro e intercambio. Como aparece recogido en la propia pagina web del ayuntamiento, estas jornadas tiene "como objetivos fundamentales, además de profundizar en el estudio de la presencia musulmana en esta zona de Al-Ándalus, establecer un nuevo horizonte que, como alternativa de carácter cultural, propicie el diá-

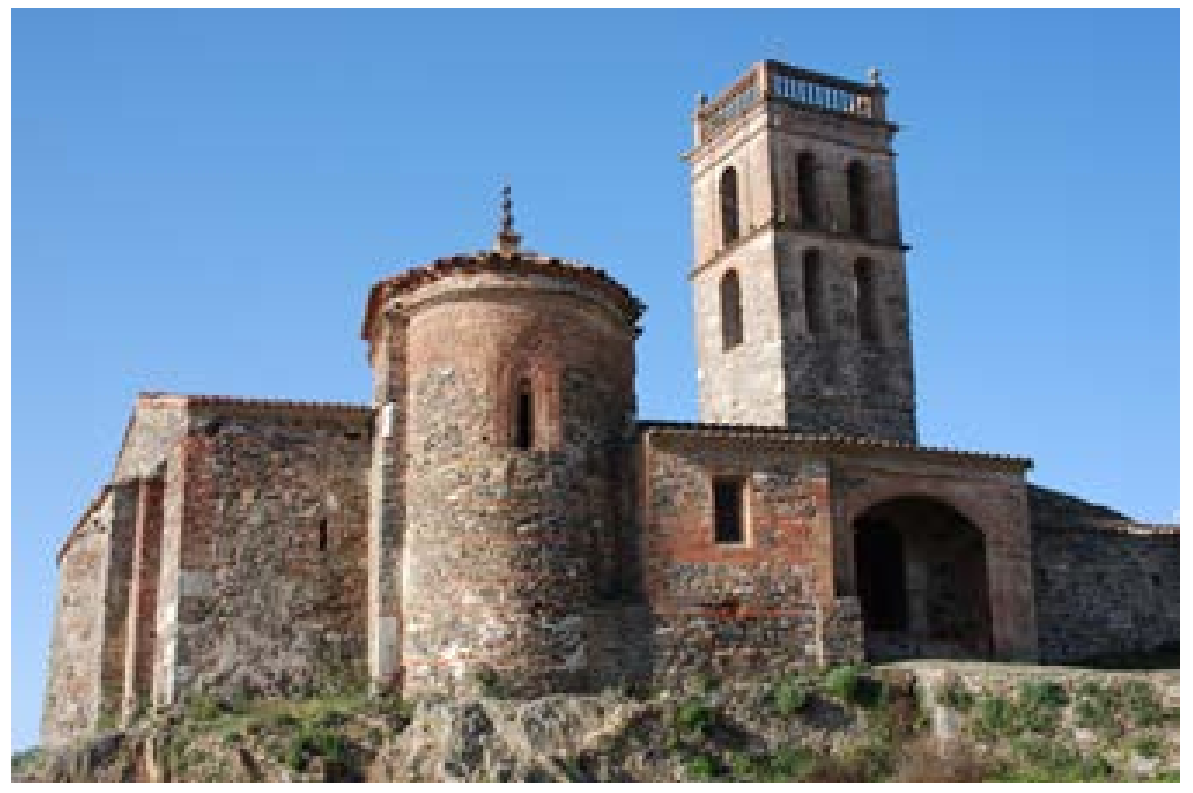

Mézquita. Almonaster la Real (Huelva) 
logo, la convivencia y el conocimiento de las culturas de Al-Ándalus a través del intercambio de experiencias e ideas, y, a la vez, sea un factor de progreso y de desarrollo para Almonaster y su entorno". De hecho, entre las recreaciones históricas con componente de revalorización islámica que se desarrollan en Andalucía, estas jornadas tienen un carácter especial al unir al Zoco y actividades de ocio las jornadas universitarias sobre historia y cultura islámica y la participación de la comunidad islámica en conferencias, rezos en la mezquita y otras actividades culturales (HERNÁNDEZ LEÓN; CASTAÑO MADROÑAL, 2014).

Otro ejemplo interesante lo encontramos en la localidad serrana de Cortegana, lugar que acoge en el verano las Jornadas Medievales. En torno al castillo de Sancho IV y calles cercanas al mismo, se reparten numerosas actividades orientadas al disfrute de visitantes. Como sucede en otros eventos similares no falta el "mercado medieval", un espacio que intenta promocionar productos locales bajo el adjetivo de "medieval".

Estos y otros ejemplos ponen de manifiesto que "Hoy todos los pueblos están renovando su capital cultural para intentar definirse y para conectarse con otros, tienen necesidad de atraer la mirada turística ajena, necesitan lograr el compromiso de la mirada ajena con la producción de ese capital cultural que quieren construir. Las dinámicas festivas de hoy ya no hay que verlas solo como espectáculos de simulación, como se hizo siguiendo a Baudrillard, también hay que verlas como rituales que adquieren trascendencia para la vida social, a pesar de las apariencias. Los espectáculos reconvertidos en rituales pueden tener importantes consecuencias sobre la negociación de conceptos por parte de la las identidades ciudadanas" (RODRÍGUEZ CAMPOS, 2010)

Como sucede en otras comarcas andaluzas (Sierra de Cádiz, Los Pedroches...) entre las propuestas encaminadas a la activación patrimonial, destacan aquellas dirigidas a la creación de un espacio de difusión bajo la denominación de museo, centro de interpretación u otros. En estos procesos es interesante subrayar que las propuestas museológicas se articulan fundamentalmente sobre el patrimonio etnológico, siendo referentes el mundo de los rituales, los oficios y otras actividades tradicionales.

En gran medida, la creación de un gran número de museos etnológicos guarda una estrecha relación con los contextos y procesos descritos con anterioridad sobre la búsqueda de activos patrimoniales orientados a las políticas de desarrollo rural, aunque los resultados de estas instituciones evidencian aspectos desiguales tanto en los procesos de creación como en el papel asignado en el conjunto de las propuestas locales de desarrollo. En numerosas ocasiones, estos espacios se convierten en contenedores de un pasado idealizado que se sumerge en los recuerdos, y que escasa- 


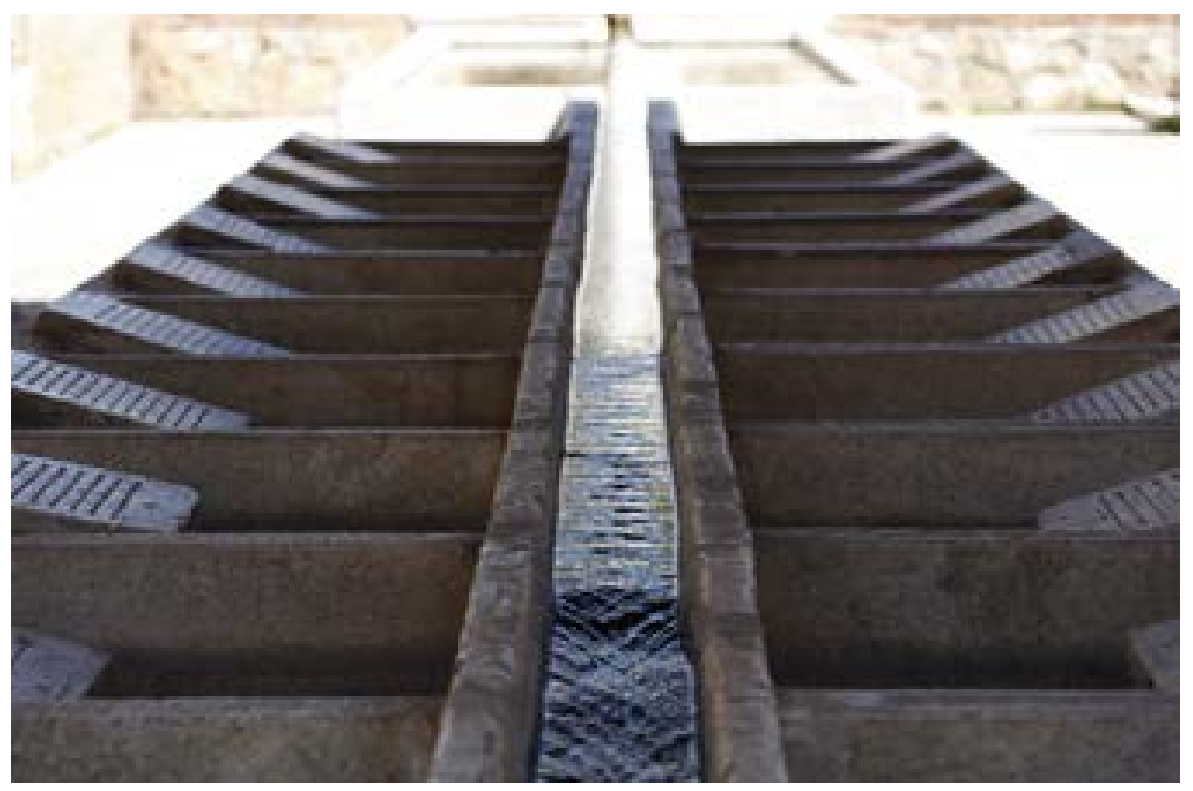

Detalle de lavadero. Aracena (Huelva)

mente valora o analiza los procesos socioeconómicos que continúan transformando nuestra sociedad.

El valor otorgado a la creación de espacios museísticos en el marco de las políticas comunitarias y el desordenado mapa de nuevos lugares destinados a la promoción de la cultura tradicional han provocado una situación compleja no exenta de interrogantes aún sin resolver.

En la Sierra de Huelva encontramos ejemplos de estos espacios museísticos en Aracena con el museo del Jamón, en Cañaveral de León con el museo del Aceite, el centro de interpretación de la cultura islámica en Almonaster la Real, el centro de interpretación de los molinos en Arroyomolinos de León, el museo etnológico de Santa Olalla del Cala, o el centro de interpretación de la Cabalgata de Reyes Magos en Higuera de la Sierra.

Otras actividades relevantes para el conocimiento y valorización de la comarca serrana son las "visitas guiadas" que distintas empresas ofrecen. En este sentido destacan las orientadas al cerdo y todo lo que rodea a su crianza y sistemas de aprovechamiento. Ocupa en este caso un papel fundamental la dehesa como paisaje cultural que vertebra una serie de actividades tradicionales perfectamente integradas en los discursos patrimoniales de esta comarca.

Estas y otras iniciativas abogan por la construcción de discursos patrimoniales que otorgan al mundo rural un papel protagonista, y en el que se suman voluntades e iniciativas tanto públicas como privadas. Ejemplos de estas son 


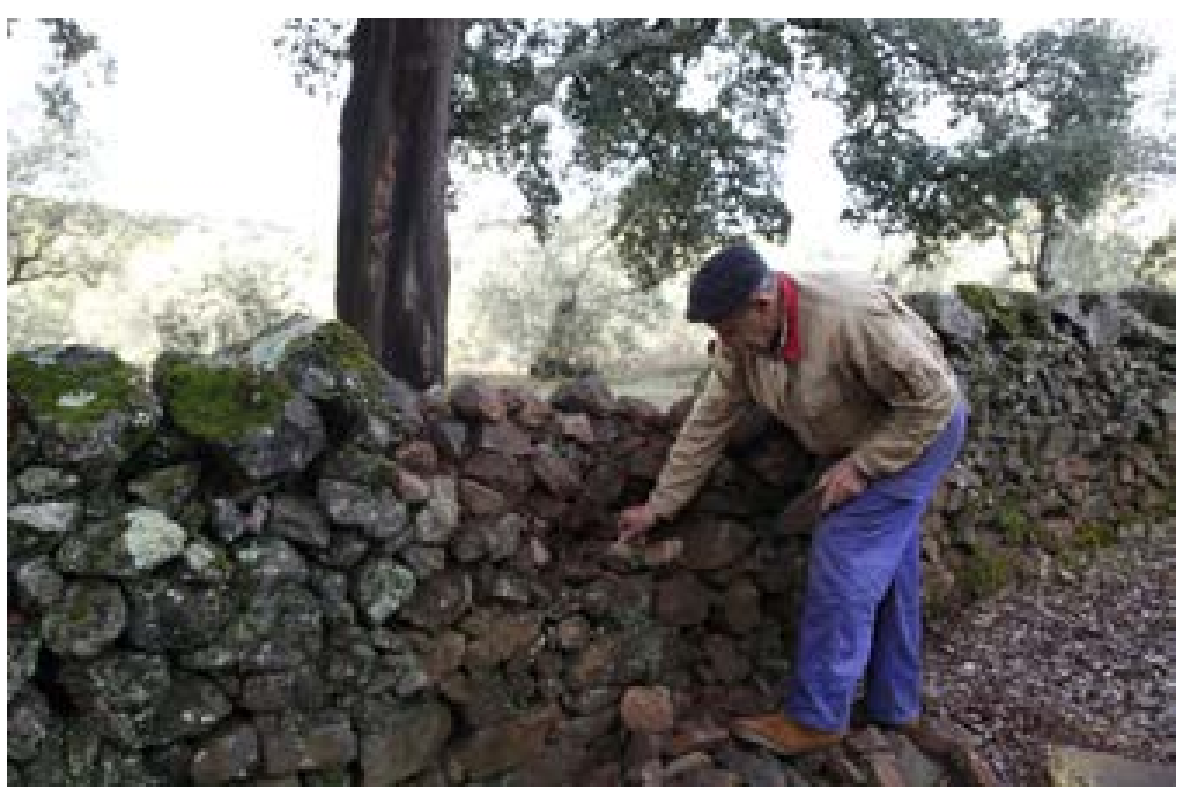

el Centro de Innovación y Promoción del Ibérico de Jabugo o las visitas que realiza la empresa Jamones Eiriz de Corteconcepción que realiza la "Ruta del Jabugo".

\section{LA PATRIMONIALIZACIÓN DEL TERRITORIO Y EL DESARROLLO RURAL}

Como hemos expuesto, mas allá de la conservación del patrimonio construido, se puede constatar una amplia dinamización de los recursos culturales patrimoniales en relación con los programas de desarrollo rural que abordan la despoblación.

La evolución en el diseño y en la ejecución de medidas para el desarrollo rural, desgraciadamente reducido al desarrollo turístico en muchos casos, ha ido mostrando una progresiva atención a los patrimonios inmateriales, que se identifican como patrimonios etnográficos en los documentos de planificación territorial y en el material de divulgación y presentación del territorio serrano. La valorización, cuando no invención, de este tipo de patrimonios ha logrado recrear con gran eficacia modos de vida tradicionales, teniendo como reverso la oposición a los modos de vida urbanos. Eficacia que no solo refiere a la productividad turística a menor coste, es decir a la relevancia que adquieren como elementos de atracción de turistas sin ser necesarias las inversiones costosas del patrimonio construido, sino más bien a la capacidad de generar experiencias de patrimonialización significativas para propios y ajenos, para vecinos seculares y nuevos residentes, para visitantes ocasionales o continuos. 


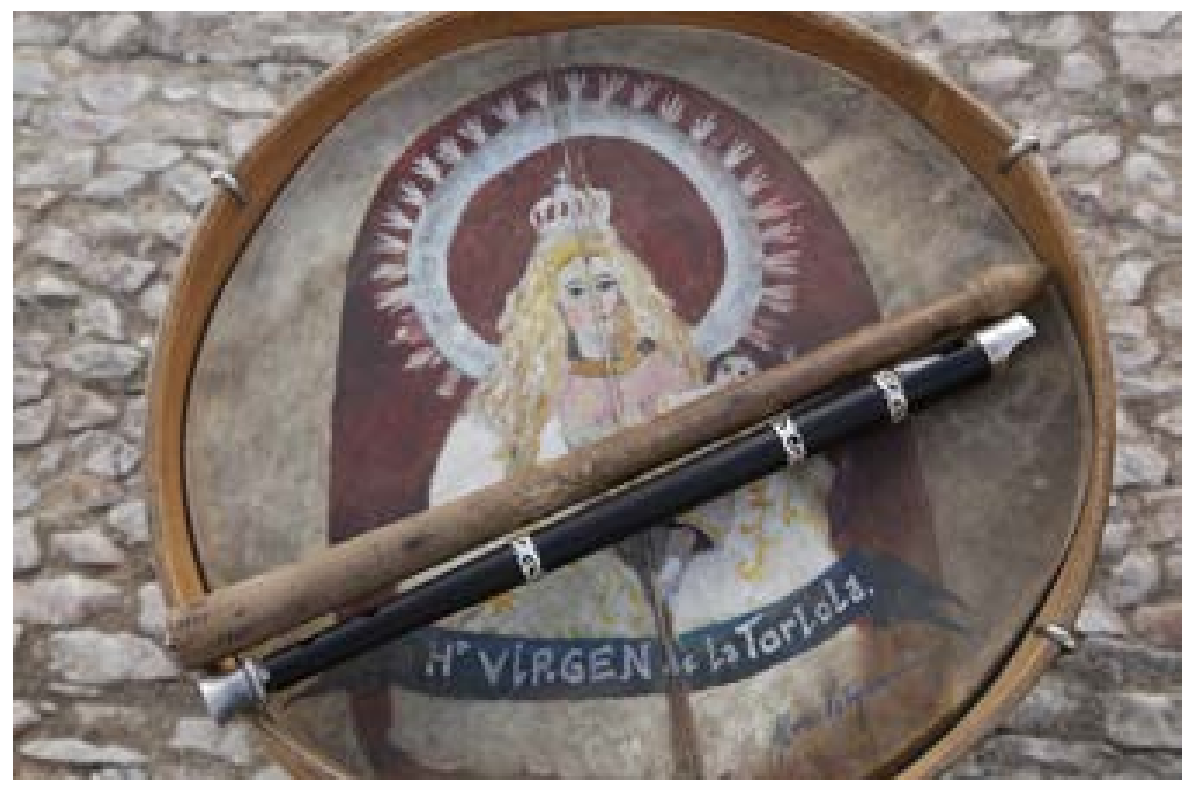

Gaita y tambor Virgen de Tórtola (Hinojales, Huelva)

El dinamismo festivo y/o de recreaciones históricas ha de observarse con las gafas de una visión crítica del patrimonio que no sólo lo asocie a la identidad autentificada sino que parta de un entendimiento diferente: "Las identidades y la memoria simplemente no se 'encuentran', 'producen' ni 'reflejan' en los sitios o momentos patrimoniales, sino que son recreadas y negociadas continuamente a medida que las personas, las comunidades y las instituciones reinterpretan, recuerdan, olvidan y revalidan el significado del pasado en cuanto a las necesidades sociales, culturales y políticas del presente (SMITH, 2006: 60).

Sólo desde esta premisa podremos analizar el papel del patrimonio en el desarrollo rural y avanzar en un análisis que trascienda el juicio experto de si la selección patrimonial es la adecuada o no. Podríamos detenernos en la crítica a unas intervenciones patrimoniales producidas en serie, de sorprendente similitud de unos elementos señalados como autóctonos con otros que no lo son, de la igualdad en la identificación de los recursos endógenos de muy distanciadas áreas, pero esta argumentación no lograría explicar por qué, aunque el patrimonio no logre revertir totalmente la despoblación, es capaz de tener éxito en el desarrollo rural de algunas zonas.

En el caso que nos ocupa, la dinamización del sector turístico es evidente desde la observación directa de estas poblaciones a lo largo de los últimos treinta años y las cifras de las que disponemos también lo corroboran, el número de plazas de alojamiento se ha multiplicado por 2,35 en diez años (DIAGNÓSTICO, 20). Establecer cuantitativamente qué parte de este aumento tiene que ver con la activación de determinados patrimonios es 
tan difícil como inútil. Mas allá de constatar la gran afluencia de público en las jornadas de recreación histórica, de ferias y de mercados y en los rituales tradicionales (cruces de mayo, romerías), los procesos de patrimonialización están incidiendo en la imagen cultural que los serranos construyen y proyectan sobre su propio territorio y ello esta íntimamente relacionado con la dinamización económica, con el valor que adquieren en el mercado los productos endógenos (HERNÁNDEZ LEÓN, 2008: 94). De hecho el patrimonio etnográfico se reconoce como parte del capital simbólico para el desarrollo territorial (II PDS, 2018: 12) y es asumido por los expertos "sin reservas las importancia del patrimonio cultural como recurso de desarrollo regional; por un lado porque goza de la capacidad de crear nuevas vinculaciones entre los agentes sociales relevantes de un cierto territorio; por otro, supone la posibilidad de que el patrimonio cultural proporcione valores simbólicos con la potencialidad de erigirse en 'indicadores culturales' y de suministrar criterios de calidad a sus productos y servicios dentro de un modelo estratégico para generar valor añadido al desarrollo territorial" (RENTING, 2010: 107).

Efectivamente, esta capacidad de generar una imagen identitaria positiva, poder adscrito y comunicativo, resulta relevante tanto para el consumo de producciones y servicios territoriales, como para que el proceso de patrimonialiación resulte exitoso al lograr ciertos consensos y narrativas de pertenencia compartidas, activadas por los agentes que entran en juego en el campo patrimonial (BOURDIEU, 2000; ARRIETA URTIZBEREA; HERNÁNDEZ LEÓN; ANDREU TOMÀS, 2016: 45).

Este campo de patrimonialización de la cultura no está exentos de diferentes pareceres y lecturas sobre un mismo patrimonio. La apuesta por el mantenimiento de la tradición podría entrar en conflicto con transformaciones e innovaciones culturales más actuales. Sin embargo el proceso de selección patrimonial apunta a la lectura de la tradición desde el presente, a una búsqueda de apropiación de un territorio afectado sobremanera por un sistema socioeconómico muy externalizado. Si la declaración de parque natural y las políticas conservacionistas supusieron la confrontación con los manejos del medio locales, la patrimonialización del territorio supone una reapropiación de éste al incidir en sus cualidades antrópicas, en la naturaleza sí, pero una naturaleza que ha sido manejada por sus habitantes (HÉRNANDEZ LEÓN, 2008: 94).

La incorporación de nuevos eventos y actividades culturales convive con el mantenimiento y revitalización de las fiestas locales completándose la serie de elementos que comunican la idea de pertenencia comunitaria local y comarcal a la vez que atrae a numerosos visitantes. No se trata de resistir a las innovaciones culturales sino que de la mano de éstas seleccionar aquellos instrumentos del pasado para promover el dinamismo socioeconómico. 
Tengamos en cuenta que no estamos hablando de una comunidad local estanca. Aunque de forma desigual en la comarca, las poblaciones serranas tienen nuevos habitantes. No solo está conformada por autóctonos sino también por extranjeros que establecieron sus residencias en los distintos municipios atraídos por las cualidades naturales y culturales del territorio. Ya sean neorrurales de las ecoaldeas, los denominados hippies, o los residentes procedentes de Sevilla y Huelva principalmente (CÁCERES FERIA; RUIZ BALLESTEROS, 2017: 5) juegan un papel fundamental en el proceso de valorización de los productos locales por sus cualidades ecológicas, en los nuevos eventos en los que venden sus artesanías o en los negocios de turismo rural.

Y este panorama de diversidad de agentes implicados en las activaciones patrimoniales se entreteje en la conformación de esa imagen de una sierra natural y cultural que puede ser consumida a través de sus productos y de sus servicios. Es aquí donde confluyen los intereses, en la posibilidad de poder volver al campo y a las manufacturas del porcino gracias a las posibilidades de un mercado local que puede ser dinámico en la medida en que se promocione la afluencia de visitantes que active el consumo, puesto que la inserción de la producción, extensiva y de medianas o pequeñas empresas, encuentra dificultades en la inserción competitiva del mercado exterior.

Además, el desarrollo de procesos participativos y fomento de la sociabilidad, formal e informal, implícitos y explícitos en las activaciones patrimoniales resultan aspectos positivos para la dinamización socioeconómica y son palpables en la continuidad y buen estado de fiestas y eventos culturales, y así se expresa al reconocer una fortaleza del territorio la singularidad comarcal y la percepción de buen lugar para vivir (DIAGNÓSTICO, 2018).

Otra cuestión es si la dinamización socioeconómica potenciada por las políticas de desarrollo rural son adecuadas en el sentido de las sostenibilidad social y ambiental. Hay que reconocer la vigencia de las desigualdades sociales y la existencia de vulnerabilidades de una población envejecida, del desempleo, principalmente femenino, y de falta de oportunidades para jóvenes, siendo amplias las necesidades de mejoras sociales para que desaparezca completamente el fantasma de la despoblación. También tener en cuenta que los beneficios son más claros en los núcleos de la sierra central con núcleos más dinámicos, así cómo las incidencias ambientales del desarrollo del turismo que tiene su cara más amarga en la presión urbanística (HERNÁNDEZ LEÓN, 2008: 95). 


\section{BIBLIOGAFÍA}

- AGUDO TORRICO, J (2012) Patrimonio etnológico y juego de identidades. Revista Andaluza de Antropología, n. ${ }^{\circ}$ 2, 2012, pp. 1-19

- AGUDO TORRICO, J; MORENO NAVARRO, I (2012) Las fiestas andaluzas. En AGUDO TORRICO, J; MORENO NAVARRO, I. (coord.) Expresiones culturales andaluzas. Sevilla: Aconcagua Libros, 2012

- ARRIETA URTIZBEREA, I.; HERNÁNDEZ LEÓN, E.; ANDREU TOMÀS, A. (2016) Patrimonio local en un mundo global: procesos de patrimonialización cultural en contextos locales de Andalucía y el País Vasco. Revista Memória em Rede [en línea], vol. 8, n. ${ }^{\circ} 14,2016$, pp. 41-57 <https:// periodicos.ufpel.edu.br/ojs2/index.php/Memoria/article/ view/7545> [Consulta: 30-09-2019]

- BARRERA LINARES, D. (2010) Los Grupos de Desarrollo Rural y la revalorización de la cultura rural como recurso para el desarrollo. En SOLER MONTIEL, M.; GUERRERO QUINTERO, C. (coord.) Patrimonio Cultural en la nueva ruralidad andaluza. Sevilla: Instituto Andaluz de Patrimonio Histórico, Consejería de Cultura de la Junta de Andalucía, pp. 162-173 (PH Cuadernos; 26)

- BOURDIE, P. (2000) Cuestiones de Sociología. Madrid: Istmo, 2000

- CÁCERES FERIA, R. RUIZ BALLESTEROS, E. (2017) Forasteros residentes y turismo de base local. Reflexiones desde Álajar (Andalucía, España). Gazeta de Antropología [en línea], n. ${ }^{\circ} 33$ (1), 2017 <http://www.gazeta-antropologia. es/?p=4947> [Consulta: 23/09/2019]

- camarero, L (coord.); CRUZ, F.; GONZÁLEZ, M.; PINO, J. A. (DEL); OLIVA, J.; SAMPREDO, R. (2009) La población rural en España. De los desequilibrios a la sosteniblidad social. Barcelona: Fundación la Caixa, 2009 (Estudios Sociales; 27). Disponible en: <https:// obrasociallacaixa.org/documents/10280/240906/vol27_ es.pdf>

- CANTERO, P. A. (2000) La matanza vegetal: rituales y usos del tomate en la Sierra. En XIV Jornadas de la Comarca de la Sierra. Huelva: Diputación Provincial, pp. 37-58

- DELGADO CABEZA, M. (2010) El sistema agroalimentario en Andalucía. En SOLER MONTIEL, M.; GUERRERO QUINTERO, C. (coord.) Patrimonio Cultural en la nueva ruralidad andaluza. Sevilla: Instituto Andaluz de Patrimonio Histórico, Consejería de Cultura, pp. 18-39 (PH Cuadernos; 26)

- DELGADO MÉNDEZ, A. (2012) Antropología, Territorio y Patrimonio. Los museos etnográficos en Extremadura. Mérida: Consejería de Cultura y Educación, Gobierno de Extremadura, 2012
- DIAGNÓSTICO territorial y Análisis DAFO (2018) [en línea] En EDL, Estrategia de desarrollo local participativo. GDRSAYPA, 2018 <http://www.gdrsaypa.es/estrategiade-desarollo-local-participativo/diagnostico-territorial> [Consulta: 01/06/ 2019)

- GARCÍA CANLINI, N. (2010) La sociedad sin relato. Antropología y estética de inminencia. Madrid: Katz Editores, 2010

- HERNÁNDEZ LEÓN, E. (2009) Patrimonios comarcales y turismo rural: ¿iniciativas locales o globales? En ARRIETA URTIZBEREA, I. (ed.) Activaciones patrimoniales e iniciativas museísticas ¿por quién? y ¿para qué? Bilbao: Universidad del País Vasco, Servicio Editorial, 2009, pp. 59-76

- HERNÁNDEZ LEÓN, E. (2005) La patrimonialización del territorio y el desarrollo rural. El caso de una comarca andaluza. En SIERRA RODRÍGUEZ, X. C.; PEREIRO, X. (coord.) Patrimonio cultural: politizaciones $y$ mercantilizaciones. $X$ Congreso de Antropología. Sevilla: Fundación El Monte, 2005, pp. 37-50

- HERNÁNDEZ LEÓN, E. (2008) De parques naturales a parques urbanos. Turismo y patrimonialización del territorio en áreas protegidas. En BELTRÁN, O.; PASCUAL, J. J.; VACCARO, I. (coord.) Patrimonialización de la naturaleza: el marco social de las políticas ambientales. XI Congreso de Antropología de la FAAEE. Donostia: Ankulegi Antropologia Elkartea, 2008, pp 83-96. Disponible en: <https://www. ankulegi.org/wp-content/uploads/2012/03/0905HernandezLeon.pdf> [Consulta: 24/09/2019]

- HERNÁNDEZ LEÓN, E.; CASTAÑo MADROÑAL, A. (2014) La geopolítica del conocimiento de la UNESCO y la semántica de interculturalidad en las políticas locales del patrimonio cultural. En GIMENO MARTíN, J. C.; CASTAÑO MADROÑAL, A. (coord.) Antropología y descolonialidad. Desafíos etnográficos y descolonización de las metodologías. Actas del 13 Simposio del XIII Congreso de Antropología de la FAAEE. Tarragona: Federación de Asociaciones de Antropología del Estado Español, 2014, pp. 3580-3602

- MORENO NAVARRO, I.; AGUDO TORRICO, J. (2012) Las fiestas andaluzas. En MORENO NAVARRO, I.;AGUDO TORRICO, J. (coord.) Expresiones culturales andaluzas. Sevilla: Centro de Estudios Andaluces, Consejería de la presidencia e Igualdad, 2012, pp. 165-207

- PÉREZ FRA, M. M. (2004) La Iniciativa Comunitaria Leader en el marco teórico de la política agraria. Revista Galega de Economía, vol. 13, n. ${ }^{\circ} 1-2,2004$, pp. 175-198

- PRATS, L. (2014) La primacía de los discursos en los usos del patrimonio. El ejemplo del patrimonio etnológico. En CÁTEDRA, M.; DEVILLARD, M. J. (ed.) Saberes 
culturales. Homenaje a José Luis García García. Barcelona: Bellaterra, 2014

- RENGIFO GALLEGO, J. I.; SÁNCHEZ MARTíN, J. M. (2016) Balance del crecimiento del turismo rural en Extremadura (1992-2015): dos décadas de éxitos y decepciones. En SANTOS SOLLA, X. M.; TABOADA DE ZUÑIGA, P.; LÓPEZ, L. X Citurdes. Congreso internacional sobre turismo rural e desenvolvimiento sistentável. Santiago de Compostela: Campus na nube, 2016, pp. 305-320

- RENTING, H. (2010) Diferentes enfoques sobre el papel de la agricultura en el desarrollo rural ¿Patrimonio cultural como efecto secundario o recurso clave? En SOLER MONTIEL, M.; GUERRERO QUINTERO, C. (coord.) Patrimonio Cultural en la nueva ruralidad andaluza. Sevilla: Instituto Andaluz de Patrimonio Histórico, Consejería de Cultura de la Junta de Andalucía, pp. 96-109 (PH Cuadernos; 26)

- RODRÍGUEZ CAMPOS, X. S. (2010) Del patrimonio local a las comunidades transnacionales. Turismo y etnicidad en Galicia. En MÁRMOL, C. DEL; FRIGOLÉ REIXACH, J.; S. NAROTZKY (coord.) Los lindes del patrimonio. Consumo y valores del pasado. Barcelona: Icaria, 2010, pp. 85-104

- ROIGÉ, X. (2016) Museos, identidades territoriales y evolución de las políticas culturales en España. En RIUSULLDEMOLINS, J.; RUBIO AROSTEGUI, J. A. (ed.) Treinta años de políticas culturales en España. Participación cultural, gobernanza territorial e industrias culturales. Valencia: Universitat de Valencia, 2016, pp. 265-283

- SMITH, L. (2006) Uses of Heritage. London \& New York: Routledge, 2006

- tAssara ANDRADE, P. (2002) Programas de desarrollo rural y patrimonio. El impacto de los fondos europeos en Andalucía. En SÁNCHEZ DE LAS HERAS, C. (coord.) Actas VI Jornadas Andaluzas de Difusión de Patrimonio Histórico. Sevilla: Consejería de Cultura, Junta de Andalucía, 2002, pp 79-92 